\title{
Medal of Honor: a história monumental em narrativas lúdicas
}

\author{
Rafael Zamorano Bezerra' \\ Christiano Britto Monteiro²
}

\section{Resumo}

Este texto apresenta algumas relações entre Games, História e Monumentos. Parte-se do princípio que o uso de referências e discursos vinculados a temas históricos na produção de games é uma forma de monumentalização de eventos passados, marcada, em alguns jogos, pela adoção de uma narrativa histórica de característica monumental, centrada na figura do herói. $\bigcirc$ argumento central da análise destaca que jogos como a franquia Medal of Honor são formas de monumentos digitais, dadas as similitudes de suas narrativas com as práticas que mobilizam a criação e a preservação dos monumentos. Analisaremos a franquia de Medal of Honor (1999) inspirada e derivada do filme $O$ resgate do soldado Ryan (1998), ambos produzidos pelo diretor Steven Spielberg.

\begin{abstract}
:
This paper presents some links between Games, History, and Monuments. We assumed that the use of historical references and discourses in the game development is a way of monumentalization of the past. It is marked, in some games, by the adoption of a Monumental History based on the figure of Hero. This work highlights that games such as the franchise Medal of Honor are Digital Monuments due to the similarities of their narratives with the practices related to the creation and preservation of Monuments. This paper analyzed the Medal of Honor franchise (1999) inspired on the movie Saving Private Ryan (1998) and produced by the film director Steven Spielberg.

\section{Keywords:}

Monuments; Games; Memory; History;WWII
\end{abstract}

\section{Palavras-chave:}

Monumentos; Games; Memória; História;

Segunda Guerra Mundial

\section{Introdução}

O objetivo deste texto é analisar as relações entre Games ${ }^{3}$, História e Monumentos. $O$ uso de referências e discursos vinculados a temas históricos na produção de games é uma nova forma de representação da história, inserida

\footnotetext{
I Historiador. Doutor em História Social (PPGHIS/UFRJ). Responsável pelo Núcleo de Pesquisa do Museu Histórico Nacional. Professor colaborador do Mestrado Profissional em Preservação e Gestão do Patrimônio Cultural das Ciências e da Saúde (COC/Fiocruz) e do ProfHistória/Unirio.

2 Professor Doutor de História (UFF).Autor da dissertação "Medal of Honor e a construção da memória da Segunda Guerra Mundial”, pelo PPGH - UFF e da tese "Medal of Honor e Call of Duty: uma comparação entre missões do videogame e eventos históricos", pelo PPGHC - UFRJ.

3 O termo game vem da expressão videogame e consiste em um jogo no qual o jogador interage com elementos gráficos por meio controles (joysticks), cuja interface ocorre a partir de aparelhos de TV ou de monitores de computador. Os sistemas eletrônicos para games são denominados como plataformas, tais como: computadores, arcades, celulares e consoles. Há uma série de videogames inventados a partir de projetos experimentais, desde 1947, entretanto, 1971 é o ano do nascimento dos games comerciais, quando a empresa Computer Space, nos EUA, criada por Nolan Bushnell e Ted Dabney, dá início a venda do primeiro arcade do mundo, baseado no jogo SpaceWar!, de 1962. In: CHAPLIN, Heather; RUBY,Aaron. Smartbomb:The quest for art, entertainment, and big bucks in the videogame revolution. Algonquin Books, 2006.
} 
na Indústria Cultural contemporânea. Esta representação histórica é marcada, em alguns jogos, por uma narrativa de característica monumental, centrada na figura do herói. Há, em narrativas destes títulos de games, um diálogo com os chamados Monumentos, e é essa relação que será analisada nesse texto. Nosso argumento procura destacar estes jogos como monumentos digitais, devido às semelhanças em suas narrativas com as práticas que mobilizam a criação de monumentos. Será analisado a série de jogos da franquia Medal of Honor, com início em 1999 e encerrada em 2013, que foi inspirada no filme $O$ resgate do soldado Ryan (1998), ambos produzidos pelo diretor Steven Spielberg ${ }^{4}$.

A noção de história monumental é compreendida a partir de Nietzsche em Sobre a utilidade e a desvantagem da história para a vida (20 I7). Para o filósofo, a relação com o futuro depende da capacidade de relação de continuidade entre passado, presente e futuro. Nietzsche entende que a História não tem apenas o propósito de obter conhecimento, mas configura-se como uma ferramenta para a modernidade. Nesse sentido, defende que deve haver um equilíbrio em nossa abordagem histórica, já que tanto a abordagem não-histórica quanto um excesso de História são prejudiciais, uma vez que a primeira inibe a reflexão enquanto a segunda prende os homens ao passado. Para ele, há três abordagens da história, a saber: a história monumental, a história antiquária e a história crítica.

A História Monumental, identificada por nós na narrativa da franquia Medal of Honor, enfatiza os grandes feitos do passado que servem como exemplos para o presente, em formulação próxima a de Cícero em sua concepção de história como mestra da vida. Trata-se aqui de valorar e valorizar as ações feitas por grandes heróis, ensinamentos ministrados por professores, monumentos, obras de arte, guerras conquistadas por heróis, que inspiram e afetam o tempo presente. $O$ passado que é valorizado é aquele monumental, que vincula os grandes momentos da história de tal maneira que assegura às gerações atuais sua grandeza. Para Nietzsche, aqueles que são incapazes de encontrar qualquer inspiração em sua vida cotidiana, olham para o passado e o monumentalizam para inspiração e motivação.

Uma outra forma de história monumental é a construção de monumentos através dos quais são celebrados a vitória e a grandeza do passado. Assim, a história monumental é uma coleção de "feitos em si" dos eventos, nos quais festas cívicas e celebrações de feitos militares são os melhores exemplos. Nietzsche afirmou corretamente que a história monumental engana através de suas analogias, uma vez que estimula o nacionalismo e uma apreensão a-crítica do passado.

A narrativa da história monumental é presente na produção cinematográfica sobre a Segunda Guerra Mundial (1939-1945), e devido a isso devemos atentar para a convergência entre cinema e games, o que possibilita apropriações, pela indústria dos jogos eletrônicos, de elementos históricos já presentes na narrativa cinematográfica. Nesse aspecto, os games vêm se tornando uma nova plataforma de divulgação da história monumental.

Entendemos que o uso de referências e discursos tipicamente vinculados a temas históricos na produção de games configura-se como uma nova forma

4 Steven Allan Spielberg (Cincinnati, 18 de dezembro de 1946) é um cineasta, produtor cinematográfico, roteirista e empresário estadunidense. É o diretor que tem mais filmes na lista dos 100 Melhores Filmes de Todos os Tempos, feita pelo American Film Institute. Spielberg venceu o Oscar de Melhor Diretor duas vezes por Schindler's List e Saving Private Ryan, também venceu o Oscar de Melhor Filme por Schindler's List. Pelo serviço prestado a valorização de veteranos recebeu uma medalha de honra no Pentágono e na época afirmou brincando:"I'm in the Army now”. DoD Honors “Private Ryan” Director Spielberg. In: http:// archive. defense.gov/news/newsarticle.aspx?id=4294 I 
de representação da história inserida na produção de mercadorias culturais da Indústria Cultural, tal como conceitualizada por Adorno e Horkheimer (1985). Essa representação histórica é marcada, em alguns jogos, pela relação com uma narrativa de característica monumental e centrada na figura do herói, em que o diálogo com os chamados monumentos históricos ocupa um lugar de destaque.

A noção de representação aqui é tomada no sentido dado pelos estudos da história cultural. Para Sandra Pesavento (2006), as representações são operações mentais e históricas que dão sentidos ao mundo e às experiências pretéritas. Para Roger Chartier (1988), representações dizem respeito ao modo como em diferentes lugares e tempos a realidade social é construída por meio de classificações, divisões e delimitações que dotam o presente de sentido. Representar historicamente algo implica tornar determinado passado em presente, o que supõe uma clara distinção entre essas duas direções do tempo.A representação, portanto, é um dispositivo de conhecimento, uma vez que permite a visualização de um ou vários passados a partir de imagens, pessoas, lugares e objetos capazes de construir memórias e histórias. Chartier (1988) pontua que esses sentidos são compartilhados e apropriados, uma vez que são historicamente construídos e determinados pelas relações de poder e conflito.

Entender, portanto, os games como representações históricas significa analisá-los como produtores de discursos e imagens sobre o passado, elementos de apropriações culturais e estéticas típicas da cultura histórica ocidental, na qual os patrimônios e as coleções museológicas são elementos inexoráveis. Significa pensá-los como importantes dispositivos de apreensão e divulgação da história, ainda mais quando se afere que seu alcance em termos de audiência é imensamente maior do que qualquer produção historiográfica produzida dentro das práticas tradicionais de divulgação de ciência. $\bigcirc$ que torna os games ainda mais interessantes é a forma na qual a representação histórica aparece na narrativa audiovisual e no seu espaço de jogabilidade, uma vez que os jogos são resultado do desenvolvimento do cinema e da computação, sendo sua particularidade expressa na relação específica entre suas estruturas de regras, composição audiovisual, construção narrativa e interatividade. (Bello; Vasconcelos, 2017).

Geralmente, a história é apropriada pelos games em duas modalidades: jogos de gerenciamento e jogos performance. Na primeira, o jogador precisa gerenciar impérios ou cidades, construindo edificações, produzindo bens de consumo, organizando exércitos, conquistando territórios etc. Exemplo clássico desta modalidade de game é o consagrado Age of Empires. Na segunda, o jogador controla um avatar ${ }^{5}$, que pode ser um personagem histórico ou fictício, que realiza ações, confrontos e desafios em uma narrativa de caráter histórico como é o caso da franquia Medal of Honor, típico de jogo de performance.

A franquia é marcada pelo avanço tecnológico na área da computação, resultante de um investimento intenso no desenvolvimento de tecnologias de processamento de dados, o que permitiu a produção de games mais complexos. Este avanço é bem representado pelos consoles da Nintendo (Nintendo), da Sony (Playstation), da Microsoft (Xbox) e pelos games desenvolvidos para computadores pessoais (Personal Computer - PC). A robusta capacidade dos processadores vem possibilitando cenários cada vez mais complexos com narrativas

5 No ambiente computacional, avatar é um cibercorpo inteiramente digital, uma figura gráfica de complexidade variada que é assumido pelos cibernautas para dentro dos mundos digitais do ciberespaço. No caso dos games, o jogador pode incorporar um ou mais destes corpos digitais, que o representam em ambientes bi ou tridimensionais, de acordo com as regras e possibilidades tecnológicas e de programação dos jogos. Neste nível de imersão, o usuário produz uma multiplicação na sua identidade, uma hesitação entre presença e ausência, estar e não estar, ser e não ser, certeza e fingimento (SANTAELLA, 2003). 
próximas às do cinema e ambientados em contextos construídos a partir de eventos canonizados pela historiografia ocidental, com destaque para os jogos de guerra inspirados em eventos históricos, como os da Segunda Guerra Mundial.

Os primeiros games domésticos como o console Atari 2600, lançado em 1977, nos EUA, e, em 1983, no Brasil, devido a baixa capacidade de processamento (6 bits) possibilitavam apenas a criação de jogos em $2 \mathrm{D}$, em áreas planas com personagens com pouquíssimos pixels e que se locomoviam de um lado para o outro, com um ponto de vista aéreo ou até isométrico para simular um ambiente 3D. Durante os anos 1990, com o desenvolvimento da chamada $5^{\text {a }}$ geração dos consoles, que marcam o avanço dos gráficos em 3D, principalmente com o lançamento, em 1993, do Nintendo 64, os criadores de games puderam explorar mais realisticamente temas históricos, produzindo jogos de bastante sucesso comercial e impressionante qualidade gráfica e pesquisa histórica, com destaque para as franquias Medal of Honor, God of War, Call of Duty, Assassin's Creed, Red Dead Redemption, Uncharted.

Nestes games, é recorrente a representação de paisagens e lugares do passado, assim como o uso de objetos históricos, ora ambientando cenários, ora atuando como fios condutores da narrativa. Obviamente, não se trata de objetos históricos propriamente ditos, e sim de imagens digitalizadas em 3D, criadas e inspiradas a partir de objetos reais, o que permite certa "simulação" ou "imersão" do player no ambiente histórico representado no jogo. Tais técnicas de "simulação" ou "imersão" são amplamente utilizadas no cinema e na televisão, por meio dos seriados e de filmes com temas históricos, gravados em locais históricos, com utilização de indumentárias, objetos e linguajar de época, entre outros artifícios cenográficos e cinematográficos. Tais recursos almejam possibilitar uma visualização do passado, técnica próxima à experiência sensorial das exposições de objetos musealizados e objetos antigos em antiquários.

A preponderância da visualidade na cultura ocidental cabe ser ressaltada, uma vez que como observado por Manoel Salgado Guimarães (2007) "somos constituídos por uma cultura oculocêntrica, que, transformada a partir do Renascimento, adquiriu a centralidade em nossa contemporaneidade" (Guimarães, 2007: 12). Sendo o saber intrinsecamente ligado à capacidade de imaginar e visualizar, ao criarem-se imagens sobre o pretérito, seja na forma de um conhecimento acadêmico específico (como a história) ou nas diferenciadas formas de representação histórica demandadas pela sociedade contemporânea (como os games), pode-se afirmar que há uma importante relação entre a capacidade de representar o passado e o mundo das imagens (Guimarães, 2007). Assim, a teatralidade presente tanto na linguagem cinematográfica como nas exposições museológicas evidenciam o papel preponderante do sentido da visão na representação histórica. Nas palavras de Ulpiano Bezerra de Meneses (1994, p. 9):

[...] a palavra "teatro", como se sabe, privilegiando a visualidade, conserva sua vinculação etimológica à família do verbo grego theáomai, ver.Assim, estas coleções de objetos materiais das mais diversas espécies organizadas pelos príncipes e senhores renascentistas, funcionavam como paradigmas visuais que recriavam simbolicamente a ordem do mundo e o espaço do exercício de seu poder. (Meneses, 1994: 9)

Os games são uma mídia audiovisual, portanto, objeto de mediações de 
seus conteúdos que, por sua vez, estão inseridos na racionalidade da indústria cultural, voltada para um mercado amplo e diversificado. Outro elemento importante é o recurso do first person, que, em jogos como Medal of Honor permite ao jogador assumir o ponto de visão do personagem do jogo no ambiente virtual. Assim, o jogador assume os braços e as armas do personagem e interage com sua nova identidade nos cenários a sua frente. Trata-se de um recurso fundamental para o efeito de catarse, que tem como característica colocar o jogador em uma condição sensorial de estar "dentro dos jogos".

Tais aspectos sensoriais associados à narrativa das crises presentes nos eventos históricos dos jogos, como o ataque à Pearl Harbor, são fundamentais para a rememoração de eventos canonizados pela cultura histórica. $O$ apelo histórico associado às técnicas do first person contribuiu para o estrondoso sucesso da versão Medal of Honor:Allied Assault, atestado pela premiação de Computer First Person Action Game of Year, no ano de 2003. Para os jogos da série Medal of Honor, este efeito insere o jogador em um ambiente que gera sua personificação, transformando-se em uma questão de identidade e valores reunidos em torno de um evento lúdico.

Os games da série Medal of Honor são estruturados em representações gráficas e códigos de reconhecimento relacionados com a história da Segunda Guerra Mundial. Para além da historiografia, podemos destacar que o conteúdo exibido é carregado de valorações nacionalistas e mitos de fundação nacionais americanos com elementos voltados para uma visão histórica bem específica e que de forma alguma dá conta da complexidade que é a sociedade estadunidense.

Ao analisar a convergência entre cinema e games estudiosos, como Cruz (2005), apontam que elementos narrativos das produções cinematográficas estão presentes nos games através de um estilo imitativo das suas técnicas, onde o cinema serve de base para a estruturação de uma linguagem audiovisual. $A$ utilização da tecnologia 3D na produção de games é fundamental nestas narrativas, pois permite um maior controle do movimento do personagem no cenário pelo player, antes limitado pelas direções ortogonais nos jogos das primeiras gerações. Já a utilização da trilha sonora se dá igualmente como no cinema: aumenta a imersão do espectador na história durante os momentos de clímax (Ferreira, 2006).

Como observa Rosenstone, o cinema tem uma importância significativa para a construção do discurso histórico, visto que por se tratar de um objeto cultural que apresenta imagens em movimento e acompanhada de sonoplastias criou mudança na maneira como contamos e vemos o passado (Rosenstone, 20I0). Isso é marcante na filmografia sobre a Segunda Guerra, principalmente na produção de Steven Spielberg, que teve um papel fundamental na construção de uma recente memória positiva acerca dos veteranos daquele conflito (Santos, 2009).

Portanto, não é fortuito o peso da visualização do passado em games de temática histórica, ainda mais quando se leva em consideração sua convergência com a narrativa cinematográfica. Todavia, esta convergência é muito mais ampla, uma vez que ocorre em várias frentes: na utilização de trailers como forma de divulgação comercial dos lançamentos; pela inserção de cutscenes $^{6}$ ao longo do

6 Cutscene, traduzido como cinemática ou curta de jogos consiste em sequência em um game sobre a qual o jogador tem nenhum ou pouco controle, é como um capítulo de filme, pois não tem jogabilidade e serve como recurso para avançar o enredo, dar sentido à história ou introduzir personagens amigos/ inimigos, podendo ter informações de fundo, atmosfera, diálogo, ou pistas. 
gameplay $^{7}$ - momentos em que o player é levado a uma posição de passividade -; e pela construção de narrativas cada vez mais próximas aos roteiros dos filmes mainstream ${ }^{8}$ de ação da indústria cinematográfica, processo que é chamado por Dee Majeck de cinamatisation (Majeck, 20l I).

Cruz (2005) observa que, da mesma maneira que ocorreu no processo descrito por Walter Benjamin para o cinema no século $X X$, os games no século XXI apropriaram-se das mídias anteriores como o cinema e a televisão borrando suas fronteiras. Este processo, chamado de remediation por Bolter e Grusin (1999), é o resultado de um desejo da nossa cultura de multiplicar suas mídias, apagando ao mesmo tempo os traços dessa mediação. Todavia, o cinema também se apropria dos games, como no uso dos gráficos digitais e de efeitos especiais, na movimentação de câmeras em cenas de ação, e no lançamento de filmes baseados em games, como as franquias Resident Evil,Tomb Raider e Assassins Creed. Exemplo bastante referenciado na literatura sobre games e cinema é o filme Corra Lola, Corra ( 1998) do diretor alemão Tom Tykwer, onde a personagem principal deve conseguir uma soma de dinheiro para seu namorado que está em apuros. Tal como em um game, ela tem um tempo regressivo para cumprir sua missão e dispõe de três vidas para atingir seu objetivo: caso morra, tem que recomeçar do início. O filme apresenta outras características dos games, como efeitos sonoros, animação por computador entre outros.

A imersão proporcionada pela experiência de jogar um game é enfatizada por uma técnica cinematográfica chamada de câmera subjetiva, onde a visão do jogador é a mesma do personagem, a partir do seu ponto de vista. É o que ocorre nos jogos first person" , no qual a franquia Medal of Honor é uma referência. Porém, tal convergência ocorre também na própria elaboração de narrativas mais complexas e modelos tradicionalmente explorados pelo universo cinematográfico, como os tipos de plano, enquadramentos das câmeras, montagem, ritmo, foco narrativo, elaboração de personagens, narrativas em primeira pessoa, nos quais os jogos tornam-se histórias interativas, limitadas apenas pelas possibilidades tecnológicas dos dispositivos.

$O$ ato de jogar tem diversas sentidos e interpretações, contudo, Johan Huizinga em seu clássico, lançado em 1938, Homo Ludens (197I) define jogar como uma atividade voluntária executada dentro de limites de tempo e espaço, de acordo com regras livremente aceitas mas absolutamente definidas, tendo seu sentido em si mesmo e acompanhado por sentimentos de tensão e prazer, com a consciência de que o jogo é algo diferente da vida ordinária. A definição de Huizinga cobre várias possibilidades, o que é interessante quando consideramos a rica genealogia que os games de caráter históricos tomaram para si. Jogos de tabuleiro, RPGs (Role Play Game) e simulações têm contribuído para a formação dos games de caráter histórico em geral. Os jogos de guerra independente da plataforma, têm mais influência sobre os jogos eletrônicos de caráter histórico, particularmente porque eles tendem a ser baseados em eventos e historicamente específicos em suas referências. Nas palavras de James Dunnigan, autor do Wargames Handbook:

7 Gameplay é a jogabilidade, ou seja, é composta pelas experiências do gamer e sua interação com os sistemas de um jogo.

8 Mainstream é a corrente de pensamento mais comum ou generalizada no contexto de determinada cultura, difundidas pelos meios de comunicação de massa. É diferente de subcultura ou contracultura e o oposto de fenômenos de culto e teorias marginais.

9 Gameplay baseado no tiro em primeira pessoa, do inglês first-person shooter (FPS), centrado no combate com armas de fogo, no qual o player enxerga-se a partir do ponto de vista do avatar, permitindo ao jogador fazer o percurso do personagem do jogo. 
A wargame is an attempt to get a jump on the future by obtaining a better understanding of the past. A wargame is a combination of "game," history and science (...) A wargame usually combines a map, playing pieces representing historical personages or military units and a set of rules telling you what you can or cannot do with them. Many are now available on personal computers. The object of any wargame (historical or otherwise) is to enable the player to recreate a specific event and, more importantly, to be able to explore what might have been if the player decides to do things differently. (Dunnigan, 2005: I 3) 10

Outro aspecto importante que vincula a franquia Medal of Honor é processo de reafirmação de valores nacionalistas e memorialistas relacionados aos eventos históricos ligados à Segunda Guerra Mundial, com o uso de imagens de época para a ambientação do jogo. Na primeira edição de Medal of Honor (1999) há uma exposição de filmes reais adicionados à abertura, tais filmes foram produzidos sob orientação da United States Office of War Information, OWI" , em 1942. Como situação inicial, há a apresentação da crise do Liberalismo instalado na Europa, que está vulnerável às conseqüências da Primeira Guerra Mundial, mas de qualquer forma há um aprofundamento dessa crise e a segue a Segunda Guerra, marcada pelo avanço do III Reich nazista (I933 - 1945) que impõe à Europa uma série de perdas através de sua expansão territorial.

\section{Memória e narrativa da II Guerra Mundial}

Como foi dito anteriormente, a franquia Medal of Honor foi inspirada no filme $O$ resgate do soldado Ryan, ambos tiveram Steven Spielberg como diretor. O jogo foi comercializado com status de superprodução. Conta também com a consultoria direta do capitão Dale Dye, um mariner veterano da guerra do Vietnã, já conhecido no mundo do entretenimento, que participa da narrativa do game. Capitão Dye já trabalhou na produção de filmes e acumula experiência de grandes sucessos, como Band of Brothers, O Resgate do Soldado Ryan, Nascido em 4 de Julho e Platoon.

Michael Pollak (1992) afirma que a memória é um fenômeno individual, mas submetido a construções coletivas. Os elementos formadores da memória, de acordo com o autor, são vividos pessoalmente (conhecidos diretamente) e vividos por tabela (conhecidos indiretamente). Neste sentido, os jogos eletrônicos são aqui concebidos como um artefato cultural que contribui para a produção de uma "vivência indireta", nos termos de Pollak, da Segunda Guerra

10 Um jogo de guerra é uma tentativa de dar um salto para o futuro, por meio de uma melhor compreensão do passado. É uma combinação de "jogo", história e ciência (...) Um jogo de guerra geralmente combina um mapa, peças que representam personagens históricas ou unidades militares e um conjunto de regras que the dizem o que você pode ou não pode fazer. Muitos estão disponíveis para computadores pessoais. O objeto de qualquer jogo de guerra (histórico ou não) é permitir ao jogador recriar um evento específico e, o mais importante, poder explorar o que poderia ter acontecido caso o jogador decidir fazer as coisas de maneira diferente. (Dunnigan, 2005:13) Tradução nossa.

II O Escritório de Informações de Guerra dos Estados Unidos (OWI) foi uma agência do governo dos Estados Unidos criada durante a Segunda Guerra Mundial.A OWI operou a partir de junho de 1942 até setembro de 1945. Através de transmissões de rádio, jornais, cartazes, fotografias, filmes e outras formas de mídia, o OWI era a conexão entre a frente de batalha e as comunidades civis. $O$ escritório também estabeleceu várias filiais no exterior, que lançaram uma ampla campanha de informação e propaganda no exterior. Para aprofundar esse tema recomendamos a obra: PEREIRA,Wagner Pinheiro. $O$ poder das imagens: cinema e política nos governos de Adolph Hitler e de Franklin D. Roosevelt (I933-1945). Alameda, 2012. 
Mundial. Para intensificar e aprofundar a catarse, há uma trilha sonora orquestral, o que colabora para uma maior ambientação e faz o jogador sentir-se em pleno campo de batalha com a sonoplastia de aviões cruzando os céus, tanques, artefatos explosivos e uma trilha sonora envolvente.

Se o que esses jogos promovem em termos mnemônicos é uma "vivência indireta", há que se relevar que há uma série de disputas e um incessante trabalho em reinterpretar o passado em função do presente e dos projetos para o futuro que cada ator delineia. Entendemos que nos games, assim como no cinema, há uma apropriação de mitos, lendas, crenças e sentimentos nacionalmente partilhados que produzem significados. $\mathrm{Na}$ busca do entendimento de tais significados compartilhamos dos apontamentos de Ana Paula Spini (2005), como a contribuição da noção do mito da guerra componente fundamental da identidade nacional no cinema de Hollywood. Para essa autora, o mito da guerra na sociedade estadunidense é investido de poesia e religiosidade.Assim, passado e presente fundem-se na imagem de homens honrados, corajosos e fiéis unidos na defesa da liberdade e da democracia. A guerra, por sua vez, pressupõe dor, sofrimento e perda. Porém, ao ser inserida na narração mítica da nação, ao contrário de torná-la insuportável, torna-a ainda mais poética e sagrada.A iminência da perda da vida humana confere aos que vão à guerra uma aura sacralizada. Combatem em nome da lealdade, da fé e da crença.A poesia na guerra é possível quando esta foi vitoriosa e reconhecida pela sociedade como uma guerra justa, ou quando representou uma perda que precisou ser elaborada - como a Guerra do Vietnã. O jogo Medal of Honor também é envolvido nestes elementos destacados pela autora. Tanto o filme $O$ Resgate do soldado Ryan, quanto a série Medal of Honor estabelecem uma relação mítica com a Segunda Guerra Mundial e com a construção da ideia do soldado herói.

$O$ filme $O$ resgate do soldado Ryan tem como ponto de partida o desembarque na Normandia, o massacre dos soldados americanos na praia é chocante e esta cena pode ser definida como um clássico do cinema de Hollywood. Spielberg impressionou gerações e este longa metragem marcou a história do cinema dos filmes de guerra e é um divisor de águas em sua carreira. Nesta obra cinematográfica, o diretor abandonou a suavidade de outros sucessos e adotou um método de exposição explícita do conflito armado, dando (através de câmeras amadoras) um ar de realidade e cobertura de jornalismo de guerra. Surpreendeu, acima de tudo, por não ser um novato e sua filmografia já apresentava títulos importantes.

O sucesso de $O$ resgate do soldado Ryan foi tão marcante para o gênero que contribuiu para a produção de Band of Brothers em formato de minissérie de TV dividida em 10 episódios, que narram a história da Companhia E (Easy Company) do $506^{\circ}$ Regimento de Infantaria Pára-quedista do Exército Americano, $10 I^{a}$ Divisão Aerotransportada na sua campanha na Segunda Guerra Mundial. Como evento central o dia 6 de Junho de 1944, o famoso Dia $D^{12}$, além da Operação Market Garden e da Batalha do Bulge. Inspirado no livro homônimo de Stephen E.Ambrose (1997).

A narrativa é marcada pela valorização da trajetória pessoal da ótica dos combatentes. Conta a campanha do regimento de paraquedistas americanos, desde sua preparação ainda em Toccoa, Estado da Geórgia nos Estados Unidos, até a tomada do Ninho da Águia, quartel general de Hitler nos Alpes em Ber-

12 O Dia D ocorreu durante a Segunda Guerra Mundial, em 6 de junho de 1944 - o dia dos desembarques na Normandia - iniciando o esforço dos Aliados ocidentais para libertar a Europa continental da Alemanha nazista. 
chtesgaden. Esta foi a série de maior orçamento da história da TV, na época. Para além do entretenimento é definida pelos produtores como uma espécie de tributo aos veteranos que são destacados como exemplo de coragem, irmandade, camaradagem e heroísmo.

Outra produção que merece destaque é The Pacific (20I0) também produzida para a TV (HBO) e no formato de minissérie. Este drama fora produzido por Spielberg, dirigido por Carl Franklin e David Nutter e baseado no livro de Robert Leckie, Helmet for my pillow (20I5). O foco central desta série é a atuação dos marines durante as batalhas dos EUA contra os japoneses no Oceano Pacífico durante a Segunda Guerra Mundial. Outros filmes produzidos por Steven Spielberg foram A conquista da honra, inspirado no livro Flags of Our Fathers (James Bradley e Ron Powers, 20I I) e Cartas de Iwo Jima. Ambos foram dirigidos por Clint Eastwood e lançados em 2006. Em comum a Batalha de Iwo Jima, no Pacífico, entre estadunidenses e japoneses. A conquista da honra trabaIhou o ponto de vista dos soldados estadunidenses e Cartas de Iwo Jima, o ponto de vista japonês, postura vista como inovadora em Hollywood. Por sua vez, A conquista da honra ressaltou a transformação da vida dos militares envolvidos na montagem da pose para a foto da colocação da bandeira dos EUA, em Iwo Jima, que resultou no maior símbolo da vitória dos EUA na Segunda Guerra Mundial.

Podemos afirmar que o diretor e produtor não somente esteve concentrado no tema da guerra nas três últimas décadas, como também deixou uma marca em seus filmes. Como Spielberg conseguiu abordar temas de guerra e conquistar multidões de variados tipos de pessoas? Atingir reconhecimento de seus trabalhos e não levar consigo a marca de brutalidade relacionada à crueza da guerra? Spielberg abordou de forma alternada, homens únicos e homens comuns sob atribuições de características únicas. Fugiu dos grandes generais e passou a olhar para a ação dos homens comuns, tratando-os com uma aura especial.Além disso, suas mais recentes produções transportam as pessoas para uma condição em que elas são as responsáveis pelos grandes acontecimentos. Suas ferramentas, no caso, as mídias (cinematográfica e dos games) são veículos de grande potencial para a divulgação destas características positivas.

Considerando os games e o cinema como mídias baseadas em "seqüência de imagens" podemos afirmar que "uma imagem é antes de tudo algo que se assemelha a outra coisa", e conforme Martine Joly:

Mesmo quando não se trata de imagem concreta, mas mental, unicamente o critério de semelhança a define: ora se parece com a visão das coisas (o sonho, a fantasia), ora se constrói a partir de um paralelismo qualitativo (metáfora verbal, imagem de si, imagem de marca). (Jolly, 1996: 38-39)

Através de imagens, que imitam o concreto, Spielberg atinge um conjunto de valores que compõem uma imagem mental dos heróis. $O$ homem comum é transportado para o universo do herói, um novo indivíduo é fabricado. Nesse ponto de vista, a Segunda Guerra é tratada como fabulosa, as pessoas são lançadas para um super foco e vistas como as autoras de todo este brilhantismo. As pessoas, principalmente os homens, são tratadas como heróis. Se os personagens abordados são pessoas comuns, porque evocar a mística do herói? 0 herói é aquele que realizará trabalhos descomunais. Desta forma ao abordar o herói, há um caminho no sentido de engrandecer seu trabalho, que no caso avaliado o trabalho é enfrentar os fascistas na Segunda Guerra Mundial e lutar 
pela liberdade no mundo.

Outra etapa que complementa a consagração do herói vai para além do reconhecimento de seus feitos e relaciona-se com o constante reconhecimento. Função social a qual os Monumentos têm a finalidade de cumprir por meio de esculturas e alegorias em praças, erguidos com a finalidade de celebrar determinada memória. A palavra "monumento" tem origem latina, monere, que significa lembrar. Na leitura de Alöis Riegl, monumento é toda obra criada pela mão do homem e construída com a finalidade de conservar viva e presente para as gerações futuras, a lembrança de determinada ação ou de uma existência. Segundo a tradição francesa, no Brasil, a construção de monumentos históricos ocorre como forma de legitimar alguns fatos e mitos fundadores da nação e de promover uma "pedagogia do cidadão". As estátuas e monumentos históricos vão sempre lembrar os "heróis nacionais" (Knauss, 2010).

Assim, as representações do passado sobre a Segunda Guerra nos games não estão em um campo vazio e constroem memórias sobre este evento histórico, assim como os acervos museológicos e arquivísticos, os patrimônios históricos, os memoriais, os cemitérios militares, os depoimentos orais, os livros, os filmes, os quadrinhos e os monumentos. Havendo a característica comum de serem representações que geram de vivências indiretas, conforme nos aponta Pollack. É justamente este aspecto que nos permite pensar nestes jogos como monumentos digitais. Estes jogos possuem em seus cenários espaços e referência sobre a Segunda Guerra. Imagens e narrativas que exploram espaços consagrados do evento são utilizados como cenários e na promoção comercial do jogo. Os momentos de grandes crises são transformados, na formulação de um discurso mítico, em uma oportunidade de superar as dificuldades e reafirmar o valor deste "povo predestinado"|3, o estadunidense, a lutar pela democracia e pela liberdade. A característica de monumento contida neste tipo de jogo torna a experiência do player uma vivência indireta (Pollack, 1992) e cobra uma atitude do jogador.Vivenciar indiretamente a Segunda Guerra pela experiência sensorial dos games, aproxima essa imersão no ambiente virtual à experiência sensorial das exposições museológicas. Principalmente aquelas de caráter histórico monumental, como as exposições de museus militares e históricos do início do século $X X$ e os living museums ${ }^{14}$ contemporâneos norte-americanos. Nessas experiências, o passado é presentificado a partir de apelos afetivos e não como elemento de desenvolvimento do conhecimento e acesso à informação. Fenômeno que vai ao encontro das ideias do crítico alemão Andreas Huyssen sobre globalização, na qual o mundo estaria se "musealizando", ao trocar o conceito (iluminista) do "progresso" pela idealização das "tradições".

Outro aspecto que nos permite pensar nos jogos como monumentos digitais é a celebração do herói anônimo, presente tanto no filme $O$ resgate do soldado Ryan, na série Band of Brothers, quanto na série de jogos Medal of Honor. Para tanto é necessário um olhar crítico sobre as obras de referência de Ste-

13 A idéia de "povo predestinado" a expandir o modelo da democracia e o modo de vida americano representou uma forma de adequação das necessidades estadunidenses de expansão à "tradição democrática" da América WASP."Na virada do século, o Caribe transformou-se numa espécie de "grande lago americano', destinado a atender à sede de investimento de uma sólida comunidade de negócios e às nascentes necessidades estratégicas e militares norte-americanas". Ver: PAMPLONA, Marco Antonio Villela. Revendo o sonho americano: 1890- 1972. Atual, 1995. Ver também: JUNQUEIRA, Mary A. Estados Unidos: a consolidação da nação. Contexto, 2001.

14 Living Museum é um tipo de experiência museal que recria cenários históricos para simular um período de tempo passado, proporcionando aos visitantes uma imersão na história ao tentar recriar ao máximo as condições de uma cultura, ambiente natural ou período histórico. 
phen Ambrose (1997), que produziu grande base conceitual para estes jogos.

As visões sobre os veteranos são variadas e, ao longo da década de 1990 , houve uma série de esforços institucionais, de setores da mídia e de organizações de apoio aos veteranos, para cristalizar uma imagem positiva deles no país. Esta tarefa teve suas maiores barreiras na Guerra do Vietnã (1964-1973), mas especificamente no veterano deste conflito, que possui a grande marca de ter sido derrotado e ao mesmo tempo de ter a pecha de ser covarde e cruel, recebendo denominações de desajustados sociais. Este veterano foi frequentemente lembrado como drogado e assassino de crianças e inocentes ao longo década de 1980, tema presentes em filmes como Platoon e Nascido para matar.

O termo baby killer foi gerado na década de 1970, após as denúncias do correspondente de guerra Seymour M. Hersh através do livro My Lai 4:A Report on the Massacre and lts Aftermath (1970), responsável por trazer à tona a tentativa do governo de encobrir o Massacre de My Lay (Vila ao sul do Vietnã), que consistiu em uma missão da Companhia Charlie, da II ${ }^{\text {a }}$ Brigada de Infantaria do Exército, de busca e destruição comandada pelo tenente William Calley, da aldeia vietnamita supostamente composta por guerrilheiros. No entanto, os militares, no dia 16 de março de 1968, massacraram centenas de civis, na maioria mulheres e crianças. Este foi o maior massacre de civis ocorrido durante a Guerra do Vietnã. Além disto, algumas das vítimas foram estupradas, torturadas e espancadas. Toda uma geração de veteranos foi marcada por este evento bárbaro. Os militares retornaram para casa e tiveram dificuldades de encontrar no próprio país um lar, uma vez que a opinião pública estava focada na luta contra a guerra destacando a ação dos soldados em campo de batalha.

Apesar disso, Spini pesquisa e expõe como a Guerra do Vietnã não se tornou um tabu na cultura norte-americana, tendo se tornado um grande filão cultural para a produção de livros, músicas, filmes de ficção, documentário, para o cinema e para a TV. Porém, para a autora há uma outra perspectiva sob a qual a guerra é tratada. Sua incessantemente rememoração ajuda no processo de enquadramento da memória, no sentido de resgatar o orgulho nacional, a instituição militar e a legitimidade da guerra como empreendimento da nação missionária. A amnésia, neste caso, consiste mais na apropriação e resignificação do acontecimento traumático do que a sua supressão.Assim, o termo massacre que no contexto Pós-guerra do Vietnã era usado para designar as atrocidades cometidas por soldados norte-americanos, sendo o massacre de My Lai o mais emblemático, ganha em Fomos Heróis outro significado. É apropriado, ressignificado, sendo o sentido anterior abandonado. No filme, as vítimas em potencial são os soldados norte americanos e os algozes são o inimigo externo. A guerra suja se transforma em guerra limpa, lavada com o sangue abundantemente derramado dos jovens soldados norte-americanos.

Por outro lado, qual o significado atribuído aos soldados estadunidenses que lutaram na Segunda Guerra Mundial? Stephen Ambrose (1936 - 2002) teve um grande reconhecimento de sua produção sobre história militar, além de ter respeito entre homens públicos do alto escalão do governo dos EUA. Suas pesquisas com veteranos da Segunda Guerra Mundial resultaram em densas descrições do cotidiano dos militares de baixa patente naquele evento. Este levantamento rendeu ao autor a pecha de relato verídico, além de ser revestida por uma percepção de que sua obra possui grande qualidade e é comprometida com a verdade. Não compartilhamos dessa visão, creditamos a Ambrose a condição de memorialista, que possui um lugar social e um papel de narrador de um projeto que envolve a valorização dos veteranos e da Segunda Guerra Mundial. 
Ambrose constrói uma narrativa histórica que vê soldados americanos como produto da condição de grandeza que os EUA estavam prontos para ocupar no cenário mundial. $O$ globalismo dos EUA teria começado justamente no período da Segunda Guerra Mundial. Para Ambrose não se trata de afirmar que os jovens que iriam para a Guerra já estavam preparados para a vida militar, mas o ambiente de democracia contribuiu para a formação de um indivíduo voltado a luta de sua liberdade e esta valorização pela sociedade democrática os mantinha em condições de superioridade. Como vemos em seu livro O Dia $D$ no qual constrói a imagem dos soldados como jovens nascidos na falsa prosperidade dos anos 1920, e que cresceram na dura realidade da depressão dos anos 1930. Para Ambrose, a literatura que eles leram quando eram garotos era antibélica, cínica, retratando patriotas como otários, molóides como heróis. Nenhum deles desejava tomar parte em outra guerra. Eles queriam estar jogando beisebol, não granadas de mão, atirando com armas calibre 22 em coelhos, não com carabinas $\mathrm{M}-\mathrm{I}$ em outros jovens, mas quando veio o teste, quando houve que escolher entre lutar pela liberdade ou abandoná-la, eles lutaram. Eram os soldados da democracia. Eram homens do Dia D, e a eles devemos nossa liberdade (Ambrose, 1997).

Ambrose influenciou a produção do game com estas exposições dos nomes dos heróis de guerra. Temos vários exemplos, como a divulgação de um dos sites oficiais, no título The Heroes of Heroes, aparecem as citações aos militares: Jimmy Patterson, William Holt, John Baker. Esses são nomes fictícios presentes na dinâmica do jogo, entretanto os nomes dos veteranos que aparecem em sites são reais.A série Medal of Honor apresenta os recursos de Ambrose e ao mesmo tempo amplia o reconhecimento dos veteranos através de uma jogabilidade que inclui uma catarse de sobreposição de identidades. Os jogadores não ficam ao lado dos veteranos, eles (no momento do jogo) são os combatentes e como todo combate acaba por ser um veterano.

O foco principal são os homens comuns, mas ainda assim as grandes autoridades aparecem em seus livros como uma espécie de coadjuvantes que preparam as cenas para os personagens principais, os soldados. A valorização do homem comum é aperfeiçoada com as relações entre sociedade civil e seus líderes, mas a liderança nos campos de batalhas é uma característica daqueles que em outras narrativas eram anônimos.

Embora os oficiais tenham destaque na narrativa, não se trata de atribuir a vitória aos grandes comandante, mas transformá-los em parte da equipe. Os exemplos de feitos de soldados, até por uma questão estatística são muito mais enumerados. Os oficiais generais são relacionados com o ambiente que foi produzido e a estrutura que deu condições magníficas para a luta, mas ao realizar uma abordagem das ações que realmente decidiram a guerra, o foco fica sobre o combatente comum, que é retratado como um gigante.

Outra obra que lançamos um olhar de correlação com os jogos foi: Soldados cidadãos, que é considerado como complemento do Dia D. Já na orelha do livro é possível perceber uma visão memorialista, que é celebrada por Colin Powell, que resume a visão principal da produção de Ambrose. É presente no imaginário da Segunda Guerra Mundial a ideia de que os militares estadunidenses foram bravos soldados americanos que derrotaram o fascismo e libertaram um continente inteiro. Nesta definição, a esfera de atribuições dos soldados está relacionada apenas ao interesse pelo bem do próximo na luta contra um inimigo terrível.

Nesta "seqüência" os soldados permanecem sendo definidos como a mais 
pura nata da sociedade americana e cumpridora daquela que seria a mais importante de todas as missões. A luta pela liberdade e o combate aos tiranos que assolam o mundo e ameaçam a integridade daqueles que não podem lutar por sua própria liberdade. Outra característica é a exibição da vitória do pensamento liberal ligado ao racionalismo. Quando a natureza perversa do homem sai de controle e ameaça ao mundo livre, os homens com seus instrumentos derivados da razão lançam mão de artifícios de força, mas com o intento de manter a estabilidade e a paz. Como nos auxilia Cecília Azevedo, ao longo do século $X X$, desenvolveu-se a noção, no EUA, de que suas instituições foram formadas através da liberdade e democracia, valores que, afirmam serem os criadores. Possuíam a crença que, ao buscarem seu destino, disseminaram as bênçãos de suas instituições sociais e política e serviriam ao propósito da humanidade. Esta noção de "Destino Manifesto"|5 , fora herdada do puritanismo dos Pais Fundadores, é uma conjugação entre os valores e princípios morais e posturas da suposta defesa do "mundo livre" (Azevedo, 2008).

Tais observações contribuem para várias relações entre a obra de Ambrose e a série Medal of Honor. Outro ponto que consideramos de grande valia são as considerações ligadas à mitologia do Oeste, que apresenta pequenos proprietários rurais, os farmers, como os autênticos pioneiros, ou seja, os self made men, aqueles que realmente conquistaram a região. A formação das mitologias é resultado de fontes que possibilitam elementos simbólicos, como imagens e metáforas e estas construções são ressignificadas de acordo com o contexto que se apresenta. Estas contribuições nos auxiliam no sentido de entendermos as representações do Medal of Honor como uma expressão resultante da cultura política presente nos discursos de reelaboração da visão sobre o veterano da Segunda Guerra Mundial.

\section{Considerações finais}

O conjunto da franquia está envolto em uma história monumental e heróica da Segunda Guerra, em especial a participação norte-americana. Trata-se de uma vivência indireta desse passado. A narrativa do game é, assim como outros do gênero, um espaço de busca pela consagração dos heróis. Trata-se de representações que não estão em um campo vazio e exercem um papel complementar às outras formas de monumentalidade de eventos históricos, como as coleções museológicas e a consagração de um discurso laudatório sobre o passado. Nesse sentido, podemos considerá-los como monumentos digitais.

Monumento é marcada pela finalidade de rememorar algo, com o recurso da afetividade e com a ação de tornar presente o passado, por meio da ação de celebrar o passado. A postura aqui assumida é de que as narrativas de games, como Medal of Honor são narrativas de monumentalização do passado que se apropriaram de narrativas e representações históricas já consagradas na cultura ocidental, por meio de diversas formas de apropriação do passado, como a história, o cinema e as práticas do celebração do passado. Assim, pode-se afir-

I5 No século XIX, a doutrina do destino manifesto era uma crença comum nos Estados Unidos que dizia que os americanos deveriam se expandir pela América. Ela expressa a crença de que o povo americano foi "eleito por Deus para civilizar o seu continente". Estaria o jornalista John O'Sullivan ligado a criação do termo manifest destiny ("destino manifesto"), em 1845, teria publicado o editorial intitulado "Anexação" onde o termo foi usado pela primeira vez, talvez escrito pelo jornalista e expansionista Jane Cazneau. Ver: «29. Manifest Destiny». American History. USHistory.org. Ver também: ETCHESON, Nicole. Mistress of Manifest Destiny: A Biography of Jane McManus Storm Cazneau, 1807-1878. The Journal of Southern History, v. 68, n. 4, p. 943, 2002. 
mar que os produtores de games são sujeitos que se apropriaram do passado e produzem narrativas históricas marcadas pela monumentalização. Tais games permitem recordar certos eventos, ressignificando-os e fazendo ligações com o passado que só é possível de estabelecer-se em sociedades históricas, como a nossa.

Os jogos eletrônicos são instrumentos de vivências indiretas que rememoram eventos e trazem para as novas gerações uma série de valores relacionados à atualidade e que se confundem com as narrativas sobre o passado. No valor rememorativo há uma possibilidade de definir qual é o sujeito do patrimônio. Tradicionalmente, é o Estado, mas vivemos o colapso e ataque do modelo de estado-nação, sendo a iniciativa privada no domínio midiático a principal elaboradora de monumentos. O patrimônio cultural é objeto de disputa econômica, política e simbólica entre o Estado, setores privados e sociedade civil. As contradições resultantes dessas disputas no uso do patrimônio têm a forma da interação entre estes setores em cada período. Obviamente, corre-se o risco de que a lógica da celebração, presente na narrativa dos games de caráter histórico analisados aqui, rivalize com uma História profissional, onde o exercício reflexivo e crítico sobre sua própria prática é o que garante sua renovação, seriedade acadêmica e função social. Cabe, portanto, ao historiador olhar para este fenômeno como um objeto de estudo, uma nova forma de representação do passado, um simulacro intimamente relacionado com as diversas formas de representação e apropriação do tempo pretérito como o cinema e os monumentos, mas também com a indústria cultural como um todo. Nesse aspecto, trata-se de um fenômeno cultural vinculado tanto à indústria cultural como à razão histórica típica das sociedades modernas, marcadas pela criação e profusão dos momentos.

\section{Referências}

ADORNO, Theodor W.; HORKHEIMER, Max. A indústria cultural: o esclarecimento como mistificação das massas. Dialética do esclarecimento, v. 2, p. I I 3- I56, 1985.

AMBROSE, Stephen E. O Dia D, 6 de junho de 1944 a batalha culminante da segunda grande guerra. Civilização Brasileira, 1997.

AMBROSE, Stephen E. Soldados cidadãos: do desembarque do Exército Americano nas praias da Normandia à batalha das Ardenas e a rendição da Alemanha, 7 de junho de 1944 a 7 de maio de 1945. Biblioteca do Exército, 2010.

AZEVEDO, Cecília. Em nome da América: os Corpos da Paz no Brasil. Alameda, 2008.

BELLO, R. S.;VASCONCELOS, J.A. O videogame como mídia de representação histórica. Revista Observatório, Palmas, v. 3, n. 5, p. 216-250, ago. 2017.

BEZERRA, R. Z. A invenção das relíquias. Dispositivos de autoridade e musealização de objetos no Museu Histórico Nacional (1922-20I2). 20I4. Tese (Doutorado em História Social) - UFRJ, Rio de Janeiro, 2014.

BOLTER, Jay David; GRUSIN, Remediation. Understanding new media. 1999.

BRADLEY, James; POWERS, Ron. Flags of our Fathers. Random House, $201 \mathrm{I}$.

CARDOSO, C. F. S. Narrativa, sentido, história. Campinas: Papirus, 1998.

CHARTIER, R. História cultural: entre práticas e representações. Lisboa: Difusão

Cultural, 1988.

CHAPLIN, Heather; RUBY,Aaron. Smartbomb: The quest for art, entertainment, 
and big bucks in the videogame revolution. Algonquin Books, 2006.

CHOAY, F. A alegoria do patrimônio. São Paulo: Unesp/Estação Liberdade, $200 \mathrm{I}$.

CRUZ, Dulce Márcia.Tempos (pós-) modernos: a relação entre cinema e games.

Revista Fronteiras - estudos midiáticos, v. 3, p. I75-184, set./dez. 2005.

DUNNINGAN, James. Wargames Handbook. How to Play and Desing Commercial and Professional Wargames. Lincoln:Willian Morrow, 2000.

ETCHESON, Nicole. Mistress of Manifest Destiny:A Biography of Jane McManus Storm Cazneau, I807- I878. The Journal of Southern History, v. 68, n. 4, p. 943, 2002. FERREIRA, E. M. Games, Cinema e Interatividade. Intercom - Sociedade Brasileira de Estudos Interdisciplinares da Comunicação. XXIX CONGRESSO BRASILEIRO DE CIÊNCIAS DA INFORMAÇÃO, 29., 2006, Brasília, DF. Anais eletrônicos... São Paulo: Intercom. Disponível em: < http://www.portcom.intercom. org.br/pdfs/l680I 28022372065036696000357|365528796I.pdf > Acesso em: 17 nov. 2017.

GUIMARÃES, Manoel Luiz Salgado.Vendo o passado: representação e escrita da história. Anais do Museu Paulista: História e Cultura Material, v. I5, n. 2, p. I I-30, 2007. http://dx.doi.org/ I0.1590/S0 I O I-47 I 42007000200002.

HERSH, Seymour M. My Lai 4: A report on the massacre and its aftermath. New York: Random House, 1970.

HUIZINGA, Johan. Homo ludens: o jogo como elemento da cultura. Editora da Universidade de S. Paulo, Editora Perspectiva, 1971.

HUYSSEN, A. Seduzidos pela memória: arquitetura, monumentos, mídia. Rio de Janeiro:Aeroplano, 2000.

JOLY, Martine. Introdução à análise da imagem. Papirus editora, 1996.

JUNQUEIRA, Mary A. Estados Unidos: a consolidação da nação. Contexto, 200 I. KNAUSS, Paulo.A festa da imagem: a afirmação da escultura pública no Brasil do século XIX. I 9\&20, Rio de Janeiro, v.V, n.4, out./dez. 20 I0. Disponível em:<http:// www.dezenovevinte.net/obras/pknauss.htm>.

LECKIE, Robert. Helmet For My Pillow [Illustrated Edition]. Pickle Partners Publishing, 2015.

LE GOFF, J. História e Memória Campinas: Ed. Unicamp, 2010.

MAJECK, Dee. The Cinematisation of Computer and Consoles Games: Aesthetic and Commercial Convergence in the Film and Games Industries. Stockholm: Stockholms Universitet, [20I I?]. Disponível em: <https://www.diva-portal.org/ smash/get/diva2:756308/FULLTEXT0I.pdf > Acesso em: 20 nov. 2017.

MENESES, Ulpiano T. Bezerra. Do teatro da memória ao laboratório da História: a exposição museológica e o conhecimento histórico. Anais do Museu Paulista: história e cultura material, v. 2, n. I, p. 9-42, 1994.

NIETZSCHE, Friedrich. Sobre a utilidade e a desvantagem da história para a vida. São Paulo: Hedra, 2017.

PAMPLONA, Marco Antonio. Revendo o sonho americano: I890- I972.Atual, 1995. PESAVENTO, S. Cultura e Representações, uma trajetória. Anos 90, Porto Alegre, v. I3, n. 23/24, p. 45-58, jan./dez. 2006.

PEREIRA,Wagner Pinheiro. $O$ poder das imagens: cinema e política nos governos de Adolph Hitler e de Franklin D. Roosevelt (1933-1945). Alameda, 2012.

POLLAK, M. Memória e Identidade Social. Estudos Históricos, Rio de Janeiro, v. 5, n. I0, p. 200-212, 1992.

POULOT, D. Museu e Museologia. Belo Horizonte:Autêntica, 2013.

POULOT, D. Uma história do patrimônio no Ocidente. São Paulo: Estação da Liberdade, 2009.

RIEGL,A. El culto moderno de los monumentos. Madrid:Visor, I987. 
ROSENSTONE, R. A história nos filmes, os filmes na história. Rio de Janeiro: Paz e Terra, 2010.

SALVATI, A. J.; BULLINGER, J. M. Selective Authenticity and the Playable Past. In: KAPPELL, M.; ELLIOT A. B. R. (Org.). Playing with the past: Digital Games and the Simulation of History. New York: Bloomsburry, 2013. p. I53-168.

SANTAELLA, Lucia. Cultura e artes do pós-humano. São Paulo: Paulus, 2003.

SANTOS, C. B. M. Medal of Honor e a construção da memória da Segunda Guerra. 2009. 128 f. Dissertação (Mestrado em História) Universidade Federal Fluminense, 2009.

SILVA, F.A.;VUGMAN, F.A relação do herói no cinema e nos jogos eletrônicos. Crítica Cultural, Palhoça, SC, v. 7, n. 2, p. 344-355, jul./dez. 2012.

SPINI, Ana Paula. Ritos de Sangue em Hollywood; mito da guerra e identidade nacional norte-americana. 2005. Tese de Doutorado. Tese de Doutorado, orientadora: Cecília Azevedo. Niterói: PPGH/UFF.

TELLES, H.V.; ALVES, L. Narrativa, história e ficção: os history games como obras fronteiriças. Comunicação e Sociedade, Braga, v. 27, p. 303-3 I7, 20 I 5. 